\title{
UNA NUEVA MIRADA A LA INCLUSIÓN FINANCIERA EN CHILE
}

\author{
Cristián Cuevas Valdés \\ ESE Business School - Universidad de los Andes
}

RESUMEN: La evidencia internacional muestra que, a pesar del crecimiento en la tenencia de productos financieros, gran parte de la población no hace uso efectivo de ellos. Este trabajo utiliza la Encuesta Financiera de Hogares 2014 para estimar un modelo probit con corrección de sesgo de selección y analizar los determinantes socioeconómicos y demográficos que influyen tanto en la tenencia como en el uso efectivo de las tarjetas de débito y crédito en Chile. Del presente estudio se derivan implicaciones de política pública. Específicamente, se encuentra que el fomento del ahorro, la complementariedad con otros activos y productos financieros y la expansión en el uso de internet tendrían un efecto positivo en desarrollar la inclusión financiera.

Palabras Clave: inclusión financiera, ahorro, crédito.

RECIBIDO: abril 2016; ACEPTADO: julio 2016.

\section{A NEW LOOK AT FINANCIAL INCLUSION IN CHILE}

ABSTRACT: Despite a significant growth in the ownership of financial products among the population, international evidence shows that in practice most of households do not effectively use these products. From the author point of view, this represents a challenge

Cristián Cuevas Valdés. Economista y magíster en economía de la Pontificia Universidad Católica de Chile. Académico del Centro de Estudios Financieros - ESE Business School de la Universidad de los Andes. Email: ccuevas.ese@uandes.cl. El autor quisiera agradecer los comentarios de Juan Gabriel Fernández así como las sugerencias realizadas por los árbitros anónimos de Estudios Públicos. 
that public policy should be more concerned. This paper uses the Chilean 2014 Household Financial Survey to estimate a probit model, with selection bias correction, to analyze socioeconomic and demographic determinants that influence both access and use of debit and credit cards in Chile. Public policy implications are derived from the paper's findings: encouraging savings, taking advantage of complementarities with other assets and financial products, and expanding the use of internet would have a positive effect on financial inclusion.

KEYWORDS: financial inclusion, savings, credit.

RECEIVED: April 2016; ACCEPTED: July 2016.

\section{INTRODUCCIÓN}

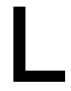

a inclusión financiera se define típicamente como la proporción de individuos que utilizan servicios financieros (Banco Mundial 2014). Ésta representa un desafío real en la actualidad, especialmente profundo si se tiene en cuenta que no basta con tener acceso a productos financieros, sino que más importante aún es que éstos efectivamente se utilicen. Al año 2014, sólo la mitad de los adultos a nivel mundial poseía una cuenta con alguna institución financiera, y en gran parte del mundo emergente dichas cuentas nunca han sido utilizadas en la práctica (Banco Mundial 2014). ${ }^{1}$ Chile se ubica en una posición ventajosa respecto a la región, pero está aún lejos de los países desarrollados. De acuerdo a la Global Findex 2014, en este país el 63 por ciento de los mayores de 15 años posee una cuenta en una institución financiera. En América Latina este número disminuye en promedio a 51 por ciento, mientras que en los países de la OCDE alcanza el 94 por ciento. Sin embargo, el resultado es aún más desfavorable si vemos que en Chile sólo el 32 por ciento de la población adulta ha utilizado efectivamente su cuenta, retirando dinero más de tres veces al mes, frente al 23 por ciento promedio para América Latina y el 66 por ciento promedio para los países de la OCDE.

${ }^{1}$ Desde el año 2009, el G20 hizo de la inclusión financiera uno de los pilares de la agenda de política financiera internacional, y es un tópico presente en la agenda de la mayoría de los reguladores bancarios (Cámara et al 2014). 
En esta línea, este trabajo explora las variables que determinan el uso en la práctica de los productos financieros en Chile. Estos pueden ser muy variados y provenir de diversos sectores de la industria financiera, $y$, en efecto, hasta el momento no existe una medida o indicador de uso generalizado que permita describir la inclusión financiera que los abarque a todos. Por lo general, los estudios disponibles se basan en la tenencia o uso de productos financieros para los que existen datos fiables en el país respectivo, siendo los más comunes las cuentas corrientes, cuentas de ahorro o créditos hipotecarios.

Este artículo explora el concepto de inclusión financiera a través del estudio de la tenencia y uso efectivo de tarjetas de débito y crédito, entendiéndose ello a lo largo del texto como sinónimo de "bancarización". ${ }^{2}$ Esta definición nos permite tomar ventaja de la Encuesta Financiera de Hogares (EFH), que en su versión 2014 por primera vez reporta datos tanto de la tenencia como de la frecuencia de uso de estas tarjetas. La importancia de poder contar con ambos indicadores radica en que estimar directamente una regresión sobre el uso de estos productos produciría un sesgo importante, ya que nuestra muestra estaría seleccionando sólo a aquellos individuos que poseen estas tarjetas. Para superar este problema, estimamos un modelo probit con corrección de sesgo de selección - modelo que permite evaluar la probabilidad de que ocurra un evento-, donde la estimación de los determinantes de la tenencia sirve de primera etapa para la posterior estimación de los determinantes del uso efectivo. Esto nos permite identificar aquellos factores socioeconómicos, demográficos y financieros que influyen tanto en la probabilidad de tener como de utilizar la tarjeta de débito y la tarjeta de crédito. En el caso de estas últimas, también se incluye un análisis de la tenencia y uso de las tarjetas de crédito de casas comerciales, con el fin de ver cómo ellas han aportado a la masificación del uso de esta forma de crédito. ${ }^{3}$ Si bien habrá algún porcentaje de la población que no tiene o no utiliza las tarjetas de manera voluntaria, se trata de identificar a aquellos hogares que, necesitándolas, tienen una

${ }^{2}$ Esta asimilación es común en la literatura sobre inclusión financiera, que se ha centrado en el estudio de los productos bancarios.

${ }^{3}$ Es importante hacer notar que al incluir las tarjetas de crédito probablemente estamos sobreestimando el acceso y uso del crédito, puesto que puede ocurrir que muchas personas las utilicen y aun así mantengan sus finanzas balanceadas. 
mayor probabilidad de no acceder a ellas por enfrentar un costo prohibitivo u otras trabas por el lado de la oferta.

Así, este trabajo aporta hacia una concepción más profunda del desafío de la inclusión financiera en Chile, puesto que va más allá de estudiar los determinantes de la mera tenencia de los productos financieros, atendiendo también al desafío de cómo lograr que se utilicen. Éste es un ejercicio que no ha sido realizado aún para el caso chileno, y la calidad de los datos permite un análisis más preciso que el disponible hasta el momento en la literatura sobre inclusión financiera en otros países en vías de desarrollo.

Los resultados indican que los ingresos del hogar y la educación son relevantes en explicar tanto el acceso como el uso efectivo de todos los productos estudiados, pero para el caso de las tarjetas de crédito encontramos evidencia de que las casas comerciales han aportado a la inclusión financiera de las mujeres y de los hogares de los deciles de ingreso más bajos. Las demás características en las que debiera poner atención la política pública para fomentar la tenencia y uso de estas tarjetas bancarias son la edad, el estado civil y si el jefe de hogar ha jubilado. Asimismo, se encuentran complementariedades entre la tenencia de otro tipo de deudas y ahorros no financieros con la tenencia de estas tarjetas, y entre otras deudas financieras y el uso de las tarjetas. Esto sugiere fomentar la educación y la práctica del ahorro en los hogares, y fomentar la tenencia de otros activos y deudas. Por último, la evidencia sugiere la expansión del acceso y uso de internet en los hogares.

Este trabajo está organizado de la siguiente manera. La sección 2 hace una revisión de la literatura relevante acerca de los beneficios de la inclusión financiera, así como de estudios que analizan sus determinantes y las políticas que la favorecen. La sección 3 describe la base de datos y presenta las principales estadísticas descriptivas. La sección 4 presenta el desarrollo empírico y sus resultados. Finalmente, la sección 5 resume las principales conclusiones y presenta una serie de recomendaciones de políticas para que el país siga avanzando en inclusión financiera.

\section{REVISIÓN DE LA LITERATURA}

La evidencia disponible ha logrado en general identificar la inclusión financiera como un elemento crítico en la reducción de la pobreza y en el logro de un crecimiento económico con mayor igualdad de in- 
gresos (Demirguc-Kunt et al. 2015). Beck et al. (2007a) encuentran una relación negativa entre desarrollo financiero y desigualdad (medida por el índice Gini), y un efecto “desproporcionadamente positivo" del desarrollo financiero sobre el ingreso del quintil más pobre, todo esto a partir de un panel de países para el periodo 1960-2005. ${ }^{4}$ Asimismo, Cull et al. (2014) hacen una revisión de aproximadamente 25 trabajos que estudian la relación entre inclusión financiera y pobreza, concluyendo que la evidencia favorece una relación positiva entre el uso de los servicios financieros e indicadores de bienestar como empleo, emprendimiento y consumo. ${ }^{5}$ Desde el punto de vista macroeconómico, cuando los países alcanzan un mercado financiero demasiado grande éste puede tener efectos negativos sobre el crecimiento (Arcand et al. 2012), ${ }^{6}$ pero aún pueden avanzar en el desarrollo económico si es que logran expandir el acceso a los servicios que este mercado provee, siendo la inclusión financiera uno de los grandes desafíos para aquellos países que han experimentado un importante desarrollo financiero en las últimas décadas, entre ellos Chile (Sahay et al. 2015).

Mientras la evidencia de los beneficios de la inclusión financiera es abundante, la literatura acerca de los determinantes que la favorecen se encuentra en pleno auge, dado por la reciente disponibilidad de nuevos datos. Si bien Beck y De la Torre (2006) aportan un marco conceptual para analizar el problema del bajo acceso a servicios financieros (instrumentos de ahorro y crédito), modelando tanto las restricciones de oferta como de demanda, desde el punto de vista empírico la principal restricción para esta literatura es la disponibilidad de datos que permitan una definición precisa de inclusión financiera, que incluya tanto tenencia como uso. Por mucho tiempo los estudios de este tipo se basaban en

${ }^{4}$ Ver Greenwood y Jovanovic (1990) para el desarrollo de un modelo teórico donde el desarrollo financiero primero favorece a los segmentos de mayores ingresos, quienes en lo inmediato están mejor preparados para invertir en el sistema financiero y obtener los mayores retornos, para luego beneficiar a una mayor proporción de la población, a medida que los segmentos más bajos logran participar de este mercado.

${ }^{5}$ Ver Karlan y Morduch (2009) para una revisión de las recientes innovaciones de política pública llevadas a cabo para expandir el acceso financiero, como microcréditos, préstamos grupales o contratos condicionados.

${ }^{6}$ Es lo que se conoce como el too much finance effect. Para una identificación más detallada sobre los mecanismos a través de los que opera, ver Cecchetti y Kharroubi $(2012 ; 2015)$. 
proxys —o variables por aproximación - muy agregadas de acceso y uso de cuentas bancarias, como número de cajeros automáticos por kilómetro cuadrado o tamaño de depósitos sobre PIB (Beck et al. 2007b; 2008).

El esfuerzo más completo a la fecha parece ser el de Allen et al. (2016), quienes utilizan la encuesta Gallup World Poor (GWP), que en 2011 incluyó una sección con tres preguntas sobre inclusión financiera: tenencia de cuentas en forma individual o conjunta, el uso de estas cuentas para ahorrar en los últimos 12 meses, y la frecuencia mensual con que se retira dinero de la cuenta. Los datos abarcan 123 países y más de 124 mil individuos. Estimando modelos probit con corrección del sesgo de selección, ellos identifican aquellos factores socioeconómicos y demográficos, por un lado, y los factores regulatorios e institucionales a nivel nacional, por otro, que son significativos en explicar la probabilidad de que un individuo esté bancarizado. Esta literatura aún no es capaz de identificar efectos causales: las correlaciones significativas son la aproximación más cercana a los determinantes de la inclusión financiera dada la disponibilidad de datos.

Entre todas las características individuales incluidas, aquellas que resultan significativas para explicar el acceso a cuentas financieras son el quintil de ingresos, la edad, la zona rural/urbana donde se habita, los años de educación, tamaño del hogar, estado civil y la situación laboral. Mientras que para explicar la probabilidad de usar la cuenta con frecuencia, es significativo además el género de la persona, donde se ve que los hombres tienen mayor probabilidad de utilizarlas con frecuencia. A la hora de revisar características regulatorias y de la industria bancaria, en general se observa que las variables significativas que originan un efecto negativo son los costos de la cuenta y sus tarjetas asociadas, y los requerimientos de información para la apertura de cuentas. Tienen un efecto positivo la penetración de cajeros automáticos (medida como cantidad por cada mil kilómetros cuadrados) y la cantidad de bancos (medida como número de bancos comerciales por cada mil kilómetros cuadrados), así como menores riesgos legales y políticos. También los autores estiman el efecto para aquellos países que cuentan con políticas que promueven el ahorro (con beneficios tributarios, por ejemplo), y encuentran un efecto positivo y significativo.

Si bien la metodología es similar a la nuestra, varias diferencias prevalecen respecto al presente estudio. En primer lugar, la GWP 2011 
pregunta por tenencia de cuentas en cualquier tipo de institución, algunas de las cuales no pertenecen al sector financiero formal y regulado, mientras que la Encuesta Financiera de Hogares (EFH) 2014 sólo incluye productos asociados a bancos y casas comerciales, lo que puede asumirse como un mecanismo de inclusión más seguro y confiable. En segundo lugar, la base de datos de Allen et al. (2016) sólo incluye alrededor de mil individuos para cada país, mientras que la EFH 2014 incluye casi cinco mil hogares, permitiendo una cobertura mucho mayor de la población y estimaciones más robustas para el caso chileno. En tercer lugar, la GWP 2011 no permite hacer ningún análisis sobre el uso de tarjetas de crédito, que son relevantes para la inclusión financiera.

Más allá del trabajo de Allen et al. (2016), en general el análisis se basa en definiciones de inclusión financiera poco precisas. Cámara et al. (2014), para el caso peruano, definen como bancarizado a un hogar que "afirma estar en al menos una de las siguientes circunstancias: percibe intereses por algún producto financiero, posee un crédito de vivienda o realiza operaciones de banca electrónica". De esta noción no sabemos si el hogar posee una cuenta bancaria, si recurre al crédito con frecuencia y ni siquiera qué sector de la industria financiera concreta se está considerando. Para el caso de Argentina, Tuesta et al. (2015), si bien analizan las cuentas bancarias, nunca distinguen correctamente entre tenencia y uso, estimando un modelo probit directamente sobre la probabilidad de uso, con todos los sesgos de selección que ello conlleva. Otro caso que ha sido estudiado es el de México, donde Djankov et al. (2008) hacen una simple comparación de características entre individuos con tenencia de cuentas con aquellos que no tienen. Sus resultados son limitados, pues concluyen que la riqueza y la educación son relevantes en explicar la tenencia, pero esto se explica por la baja calidad de los datos que poseen. En cambio, Peña et al. (2014) analizan los determinantes de un indicador agregado de inclusión financiera para México, en el que sin embargo no es posible distinguir entre la tenencia y el uso.

Desde una perspectiva algo distinta, Greene y Rhine (2013) estudian el proceso dinámico por el cual una familia en Estados Unidos sale del sistema bancario (cierra su cuenta de ahorro). Sus resultados sugieren que aumenta la probabilidad de salida cuando cae el ingreso familiar, se pierde el empleo o se pierde cobertura en el seguro de salud. Las principales características socioeconómicas que determinan la par- 
ticipación de la familia en el sistema financiero serían la raza, el nivel de educación, el estado civil de la cabeza del hogar y el régimen de propiedad de la vivienda.

Campbell et al. (2012) identifican los determinantes del cierre involuntario de cuentas bancarias entre 2002 y 2005 , ya sea por sobregiro o el abandono de la cuenta. Su metodología consiste en una sencilla estimación por mínimos cuadrados ordinarios, agregando algunos efectos fijos para aquellas variables que varían entre años. Sus resultados indican que el cierre de cuentas no está relacionado con la pobreza (el fenómeno se extiende más allá de ella). Después de controlar por ingreso, activos financieros, pobreza, estructura familiar y desempleo, los autores encuentran que el cierre involuntario de cuentas está relacionado con la habilidad de los consumidores de planificar gastos, el grado de expansión geográfica de los bancos (con los bancos locales menos propensos a cerrar cuentas) y la disponibilidad de créditos fuera del sistema bancario. Los autores reconocen que no pueden descartar la existencia de variables omitidas, pero afirman que resulta difícil pensar en alguna dada la gran cantidad que sí fueron incluidas.

El caso chileno aún no ha sido abordado en profundidad por la literatura académica. Marshall y Kaufmann (2013) analizan exhaustivamente el comportamiento financiero de los jóvenes, pero sólo a nivel de tenencia de cuentas y tarjetas de crédito. Asimismo, Marshall (2015) realiza un diagnóstico acerca de la práctica del ahorro entre la población, pero ésta es sólo una de las dimensiones de la inclusión financiera: pueden haber individuos que utilicen cuentas bancarias pero no necesariamente para ahorrar. Así, este trabajo busca ser el primero en analizar con un mayor grado de profundidad la inclusión financiera en Chile, abarcando las dimensiones de tenencia como de uso frecuente de las tarjetas de débito y crédito.

\section{ESTADÍSTICAS DESCRIPTIVAS}

La Encuesta Financiera de Hogares (EFH), realizada por el Banco Central de Chile, tiene por objeto la caracterización del balance financiero y de los ingresos de los hogares en Chile. Se ha realizado anualmente desde 2007, con la sola ausencia en el año 2013. El levantamiento de 2014 tuvo carácter nacional urbano, entrevistando 4.502 hogares. 
Para graficar la brecha entre tenencia y uso efectivo, resulta ilustrativo comenzar nuestro análisis mostrando las principales estadísticas de inclusión financiera. ${ }^{7}$ La figura 1 muestra la proporción de hogares que tienen cada una de las tarjetas junto con la proporción de hogares que declara usarla al menos semanalmente (para esta sección, esta frecuencia de uso es arbitraria y tiene el único propósito de ilustrar el fenómeno).

Mientras casi el 80 por ciento de los hogares declara poseer una tarjeta de débito, sólo el 38 por ciento dice usarla con una frecuencia al menos semanal. Esta brecha es aún más drástica para el caso de las tarjetas de crédito, donde la diferencia más grande entre tenencia y uso se da para las de casa comercial. Estos datos están en línea con la evidencia internacional citada en nuestra introducción: el hecho de tener una tarjeta no implica que esta se use en la práctica y la política pública debiera distinguir entre ambas dimensiones para fomentar la inclusión financiera.

\section{Figura 1. HOGARES E INCLUSIÓN FINANCIERA}

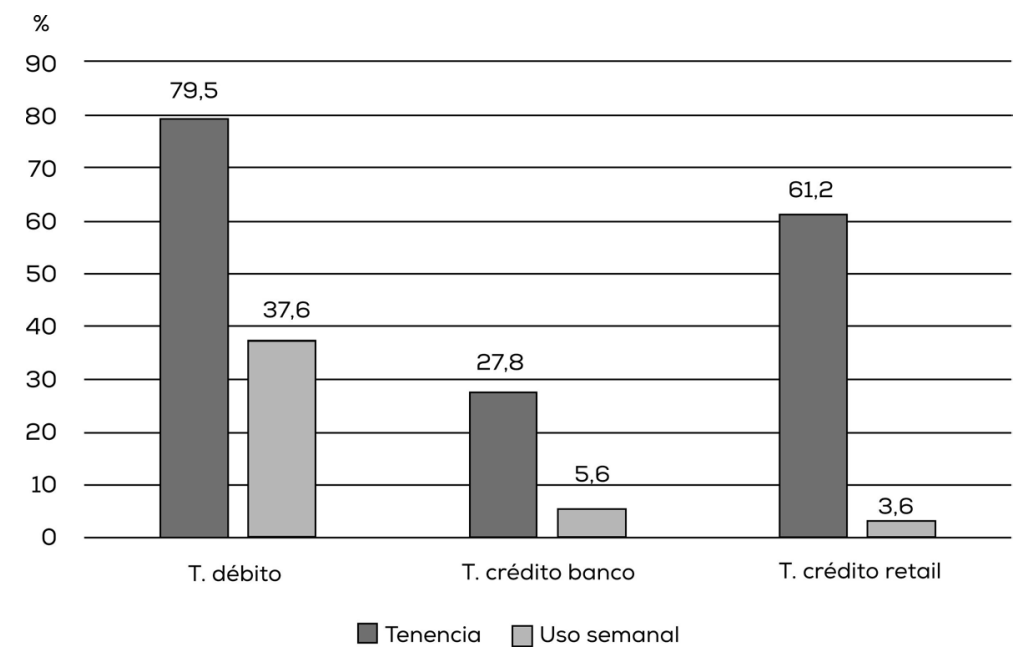

Fuente: Elaboración del autor en base a encuesta EFH 2014.

${ }^{7}$ Dado que ésta es la primera versión de la EFH que reporta tenencia y uso de tres tarjetas (de débito, crédito y de retail), no es posible construir una serie comparable para observar la evolución de la inclusión financiera en los últimos años. La encuesta Casen reporta tenencia de tarjetas de débito y crédito en 2011 y 2013, pero hay diferencias en cómo se hicieron las preguntas. 
Figura 2. HOGARES E INCLUSIÓN FINANCIERA, POR DECIL

\section{A. Tenencia}

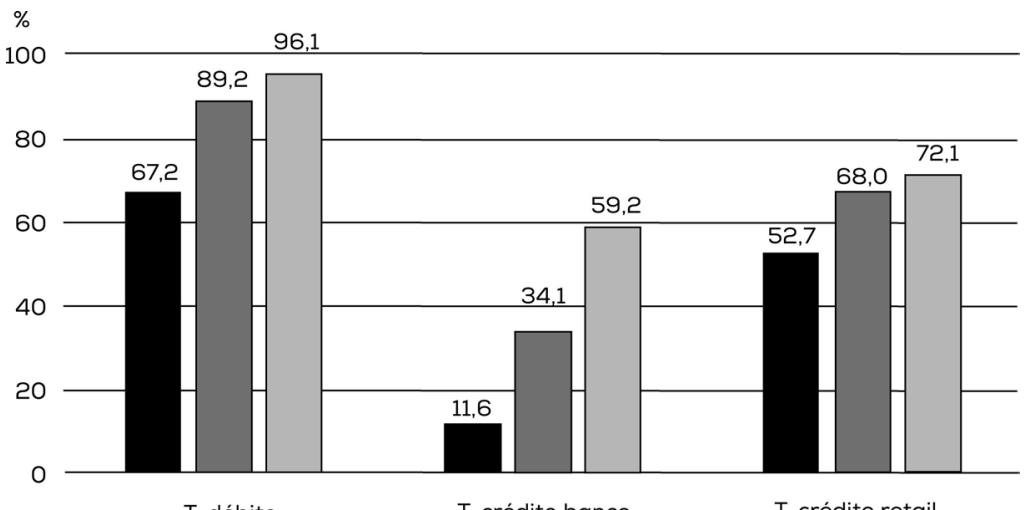

T. débito

T. crédito banco

T. crédito retail

$\square$ Deciles 1 al $5 \quad \square$ Deciles 6 al $8 \quad \square$ Deciles 9 al 10

\section{B. Uso semanal}

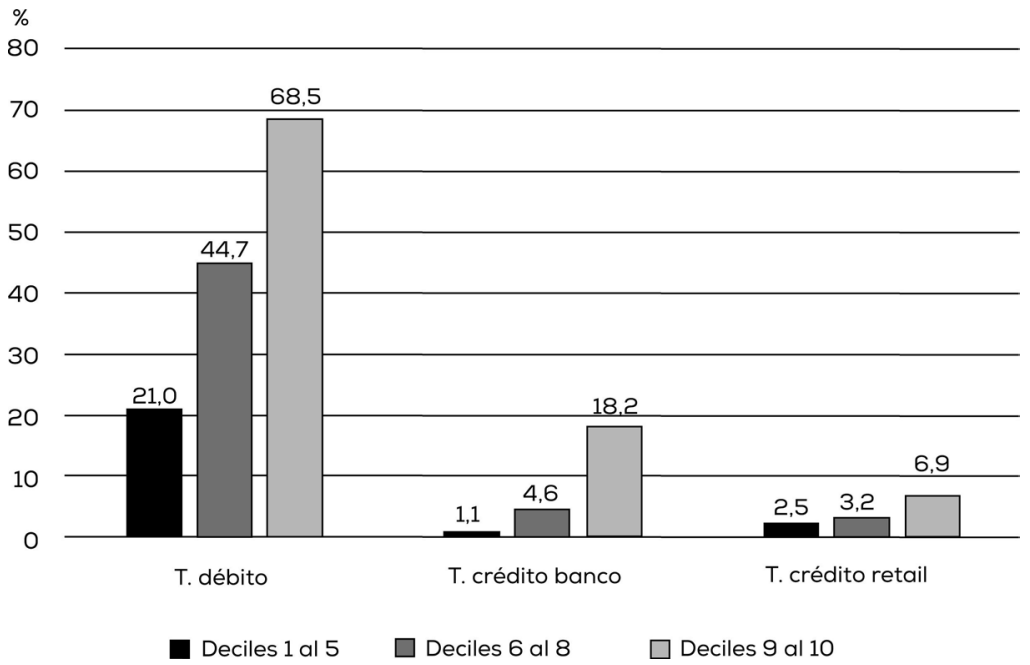

Fuente: Elaboración del autor en base a encuesta EFH 2014. 
La figura 2 muestra una fuerte relación entre inclusión financiera y decil de ingreso. Por el lado de las tarjetas de débito, esta relación puede darse debido a que quienes poseen mayor ingreso tienen, por un lado, más necesidad de una cuenta donde almacenarlo y, por otro, mayores posibilidades de pagar los costos asociados. Por el lado de las tarjetas de crédito, los mayores ingresos funcionan como un buen respaldo financiero, que dispone a los bancos a entregar este producto. Lo que llama la atención de la figura 2 es que la tenencia de tarjetas de débito y de crédito retail posee una distribución más igualitaria que las de crédito bancarias. Los tres grupos de hogares mostrados presentan una mayor tenencia de tarjetas de casa comercial que de tarjetas bancarias, lo que ilustra su mayor presencia en los deciles más bajos (aunque a nivel de uso semanal predominan las bancarias). Asimismo, el uso semanal de la tarjeta de débito exhibe importantes diferencias entre los tres grupos de hogares.

La figura 3 muestra el acceso de los hogares según la edad del jefe de hogar, para lo que definimos cuatro rangos: 18 a 24 años, 25 a 39 años, 40 a 64 años y más de 65 años. Analizar la edad es interesante por varias razones, puesto que, por ejemplo, nos puede hacer ver si es que las generaciones más jóvenes están más bancarizadas, lo que podría predecir una mayor inclusión financiera futura, cuando estas cohortes predominen en la población.

Entre los jefes de hogar menores a 40 años predomina la tenencia y uso semanal de las tarjetas de débito y de crédito retail. Llama la atención que en esta última los jefes de hogar entre 18-24 años muestran una tenencia y uso sólo levemente inferior que en los rangos entre 25-39 y entre 40-64. Sería razonable pensar que en el rango de edad más joven haya menor tenencia y uso de tarjetas de crédito, puesto que el perfil de ingresos que la respalden debiera ser menor. Observamos, sin embargo, que las casas comerciales han logrado ingresar a este segmento en mayor medida que los bancos. Por último, hay que notar que para las tres tarjetas (débito, crédito bancario y crédito retail) se observa una caída en la tercera edad, tanto en la tenencia como en el uso. 
Figura 3. HOGARES E INCLUSIÓN FINANCIERA, POR EDAD DEL JEFE DE HOGAR

\section{A. Tenencia}

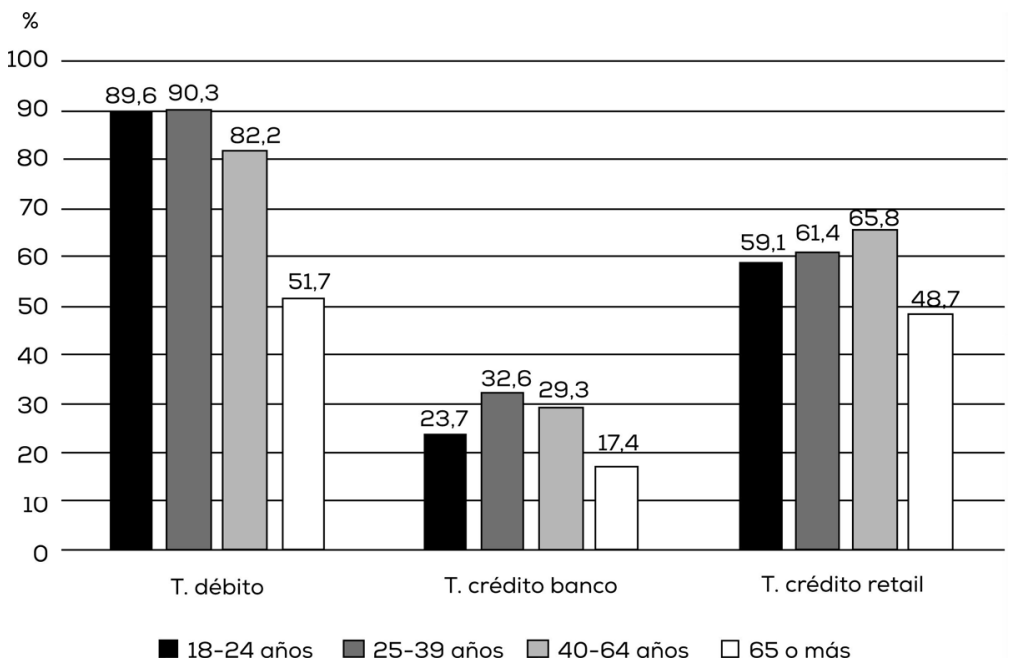

B. Uso semanal

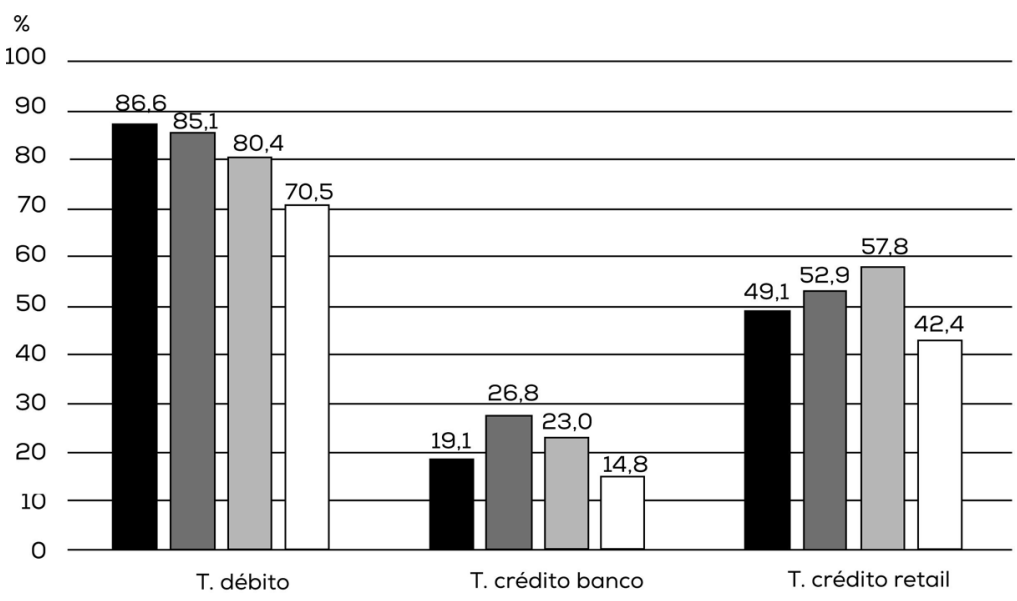

घ 18-24 años $\square$ 25-39 años $\square$ 40-64 años $\square 65$ o más 


\section{EVALUACIÓN EMPÍRICA}

\subsection{Metodología}

La pregunta que queremos responder es: ¿cuáles son los factores que influyen en la tenencia y en la decisión de usar con frecuencia las tarjetas de débito y crédito? Para estudiar los determinantes de la tenencia estimamos un modelo probit estándar sobre el total de la población, en el que la variable dependiente toma el valor de 1 si el hogar posee la tarjeta y 0 si no. En cuanto a los determinantes del uso frecuente, la dificultad de un ejercicio como éste se origina en la selección de la muestra, puesto que sólo observamos hogares que poseen estas tarjetas y, como se desprende de la sección anterior, la tenencia no sería aleatoria. Sin embargo, este problema puede ser abordado estimando un modelo probit con corrección de sesgo de selección conocido como heckprob, propuesto por Ven y Van Praag (1981). Este modelo corrige por el hecho de que el uso frecuente de las tarjetas sólo se observa para hogares que las poseen. Así, la decisión de tenencia se modela conjuntamente con la decisión de utilizarlas.

Definimos $Y_{1 i}$ como una variable dicotómica que toma valor igual a 1 si el hogar usa la tarjeta con frecuencia y 0 si nunca la utiliza. Sea $Y_{2 i}$ una variable dicotómica que toma el valor de 1 si el hogar tiene la tarjeta y 0 si no. Luego, el modelo probit que queremos estimar está dado por la siguiente ecuación:

$$
Y_{1 i}= \begin{cases}1 & \text { si } y_{1 i}^{*}>0 \text { y } Y_{2 i}=1 \\ 0 & \text { si } y_{1 i}^{*} \leq 0 \text { y } Y_{2 i}=1 \\ \text { no obs } & \text { si } Y_{2 i}=0\end{cases}
$$

Donde la variable $y_{1 i}^{*}$ es una variable latente de decisión de frecuencia de uso. Nótese que tenemos selección y sólo observamos $Y_{1 i} \mathrm{si}$ $Y_{2 i}=1$. En el caso de que $Y_{2 i}=0$ no observamos $Y_{1 i}$ y tenemos un missing value. La ecuación de selección es:

$$
Y_{2 i}= \begin{cases}1 & \text { si } y_{2 i}^{*}>0 \\ 0 & \text { si } y_{2 i}^{*} \leq 0\end{cases}
$$

Y las ecuaciones para las variables latentes están dadas por

$$
\begin{aligned}
& y_{2 i}^{*}=z_{i} \delta+v_{2 i} \\
& y_{1 i}^{*}=x_{\mathrm{i}} \beta+v_{1 i}
\end{aligned}
$$


donde se supone que el vector $\left(v_{1 i}, v_{2 i}\right)$ se distribuye como una normal bivariada con media $(0,0)$, varianzas $(1,1)$ y correlación $\rho$. Obsérvese que, así como está presentado el modelo, tenemos tres realizaciones posibles para el vector $\left(Y_{1 i}, Y_{2 i}\right):(1,1),(0,1)$, (no observada, 0$)$. La función de verosimilitud para el caso simultáneo se puede formular de la siguiente manera:

$$
\begin{aligned}
l(\beta, \delta, \rho)= & \sum \ln \left\{\Phi_{2}\left(x_{i} \beta, \mathrm{z}_{i} \delta, \rho\right)\right\} Y_{1 i} Y_{2 i}+\sum \ln \left\{\Phi_{2}\left(-x_{i} \beta, \mathrm{z}_{i} \delta,-\rho\right)\right\}\left(1-Y_{1 i}\right) Y_{2 i} \\
& +\sum \ln \left\{1-\Phi\left(\mathrm{z}_{i} \delta\right)\right\}\left(1-Y_{2 i}\right)
\end{aligned}
$$

donde $\Phi_{2}$ corresponde a la función de distribución acumulada de una normal bivariada. Es importante señalar que cada término del lado derecho de la ecuación corresponde a una de las tres posibles realizaciones para el vector $\left(Y_{1 i}, Y_{2 i}\right)$ en el orden respectivo, y que las distribuciones son conjuntas. Esto es lo que se conoce como heckprob y la estimación de la ecuación anterior se realiza por máxima verosimilitud. Para una correcta identificación del modelo, debe haber al menos una variable en la ecuación de selección que no esté presente en la ecuación principal.

Para este modelo heckprob la variable dependiente $\left(Y_{1 i}\right)$ toma valor igual a 1 si el hogar usa la tarjeta con cualquier tipo de frecuencia ("diaria", "varias veces a la semana", "semanal", "quincenal", "mensual" u "ocasional") y 0 si declara no utilizarla. ${ }^{8}$ Es importante notar que, dada su naturaleza de corte transversal, los datos no nos permiten interpretar los resultados como efectos causales, sino como correlaciones significativas.

La tabla A1 - en el anexo- detalla la definición exacta de cada variable explicativa incluida. El signo del coeficiente asociado a "mujer" debiera indicar la existencia de una brecha de género en la tenencia o uso de las tarjetas. Si el signo es negativo, querrá decir que para las

${ }^{8}$ Agrupamos las seis frecuencias consideradas en las respuestas de la encuesta en un solo grupo, ya que, dada la gran cantidad de observaciones en las que se declara no usarla, esta separación es la única que da una cantidad suficiente de observaciones 0 y 1 para la estimación del modelo. Otra opción que intentamos fue estimar un modelo probit ordenado con ecuación de selección, utilizando las seis respuestas como outcomes distintos, pero varios de estos quedaban con tan pocas observaciones que la estimación no era posible. 
jefas de hogar es más difícil tenerlas o usarlas. Tanto la variable de estado civil como la de número de ocupados en el hogar debieran tener un signo positivo, puesto que hay más individuos en el hogar que puedan tener o usar dichas tarjetas. Para la variable edad, la simple intuición permite aventurar dos efectos opuestos. Por un lado, los más jóvenes podrían tener menores ingresos o menor experiencia financiera y tener o utilizar menos estas tarjetas; o, por el contrario, tener la capacidad de adaptarse mejor a esta tecnología y experimentar una mayor probabilidad de tenerla o utilizarla con más frecuencia que los mayores. Para la variable de años de educación y la que indica si el jefe de hogar trabaja, esperamos un signo positivo tanto en tenencia como en uso frecuente. La educación, más allá de su correlación con ingresos, puede ser indicativa de una mejor educación financiera, y el trabajar implica mayor disponibilidad de recursos que permiten tener en dinero en la tarjeta de débito y acceder a tarjetas de crédito. Si el hogar pertenece a los deciles más pobres ( 1 a 8 ) debiera tener un efecto negativo tanto sobre la tenencia como sobre el uso frecuente de las tarjetas. Para los hogares con jefes de hogar jubilados debiera estimarse un signo negativo, puesto que es más probable que su disponibilidad de recursos empeore.

Las variables de ahorros y deudas no financieras (automotrices, educacionales y otras) se incluyen porque pueden ser informativas acerca de si las políticas de fomento del ahorro o de provisión de créditos influyen en la bancarización. Ésta es una discusión de larga data en la literatura académica, en la que se estudia si las políticas de fomento del ahorro o el fomento de los microcréditos son las que facilitan la inclusión financiera (entendida muchas veces de manera amplia) en los países en desarrollo (ver Karlan y Morduch 2009 para un desarrollo de los mecanismos a través de los cuales ocurren estos efectos). Si bien nuestros resultados no implican necesariamente efectos causales, un signo positivo de la variable "ahorro no trad." indicaría una relación positiva entre la práctica del ahorro y la inclusión financiera entendida como tenencia y uso de tarjetas bancarias. De la misma manera, un signo positivo de las variables de deudas automotrices u otras podría ser interpretado como un apoyo a la política de educar en el endeudamiento y facilitar el acceso a microcréditos.

Por último, un signo positivo para las variables de deudas y activos financieros indicaría la existencia de complementariedades entre éstas y 
el uso frecuente de las tarjetas. Si bien no existe mucha literatura sobre la existencia de este efecto ni de los mecanismos a través de los cuales se produce, la intuición nos dice que esta complementariedad puede darse por mayores conocimientos financieros previos o adquiridos a través de estos servicios; o que estos activos pueden implicar mayor disponibilidad de recursos, lo que motiva a manejarlos a través de cuentas bancarias asociadas a tarjetas de débito o facilita la cantidad de recursos disponibles en la tarjeta de crédito. En este trabajo no es posible aún distinguir entre mecanismos dada la limitación de los datos para hacer ese análisis. La variable internet debiera tener un signo positivo dado que facilita el uso de los fondos asociados a estas tarjetas.

\subsection{Resultados}

La tabla 1 presenta los resultados de la estimación de los modelos probit y heckprob para las tarjetas de débito. Las columnas 1 a 4 estiman un modelo probit estándar para los determinantes de la tenencia, donde la variable dependiente toma el valor de 1 si el hogar posee la tarjeta y 0 si no, asumiendo distintas especificaciones donde las variables de ahorros y deudas no financieras se incluyen por separado. Las columnas 5 a 8 estiman un heckprob para los determinantes del uso frecuente de los hogares que poseen tarjetas, utilizando el modelo de la columna 4 como ecuación de selección, y donde las variables de activos, deudas y uso de internet se incluyen progresivamente.

Los resultados de la estimación son interesantes. Primero, todos los modelos son significativos de acuerdo a la prueba convencional del test de razón de verosimilitud y, en general, los parámetros son robustos a las distintas especificaciones. En lo que sigue, para analizar los resultados escogeremos la especificación que recomiende el criterio de información de Akaike (mediante el cual se comparan modelos de acuerdo a su varianza y complejidad, donde el que reporta el menor valor es el más plausible).

En las columnas 1 a 4, además de controlar por variables socioeconómicas y demográficas, incluimos la tenencia, por parte de algún miembro del hogar, de deudas automotrices, educacionales, otras deudas no bancarias (parientes, empleador, fiados, prestamistas, entre otras) y la tenencia de ahorros no bancarios (negocios familiares, pollas, entre otras). Es importante que estas variables de deudas y ahorros se refieran a fuentes no bancarias, ya que en caso contrario estaríamos incluyendo 
entre las variables explicativas determinantes que ya constituyen bancarización. Por la misma razón no se incluye la variable internet, que mide si es que el hogar realiza operaciones de banca electrónica.

La columna 2 es la más informativa según el criterio de Akaike. En ella vemos que el número de ocupados en el hogar, la educación y la situación laboral del jefe de hogar, más la tenencia de ahorros no bancarios tienen un efecto significativo y positivo sobre la tenencia de tarjetas de débito, mientras que los hogares de los deciles de ingreso más bajos tienen menor probabilidad de poseerlas. El signo de estas variables está de acuerdo con la intuición y los parámetros son robustos a las distintas especificaciones. El sexo del jefe de hogar y la tenencia de deudas no bancarias no son estadísticamente relevantes.

Para analizar los determinantes de la decisión de usar la tarjeta de débito con frecuencia nos centramos en la columna 8. Como se explicó en la subsección anterior, para una correcta identificación de los modelos debe haber al menos una variable en la ecuación de selección que no esté presente en la ecuación de resultados. En este caso excluimos el número de miembros no ocupados en el hogar. Añadimos como variables explicativas la tenencia de deudas de consumo e hipotecarias, de activos reales y financieros y el uso de la banca electrónica (internet). En este caso no hay inconvenientes en incluir estas variables, puesto que al medir uso ya sabemos (y corregimos por el hecho de) que el hogar tiene ya una relación con algún banco. En otras palabras, la tenencia de estos servicios financieros no es independiente del hecho de tener tarjetas de débito, pero sí es independiente del uso que se hace de ellas.

Un análisis por variables para la ecuación de uso debe considerar que la categoría de comparación es el no utilizar la tarjeta. Así, por ejemplo, se observa que la probabilidad de usar la tarjeta de débito es significativamente mayor mientras mayor es el número de ocupados en el hogar y se utiliza internet. Los hogares con jefe de hogar jubilado, coherentemente con la intuición, son menos propensos a utilizar la tarjeta, lo que sugiere que debieran ser un público objetivo de posibles programas públicos y privados orientados a mejorar los niveles de bancarización. Además, la tenencia de deudas de consumo y activos reales favorecen que el hogar haga uso frecuente de esta tarjeta, lo que sería indicativo de una complementariedad entre el uso efectivo de estos productos financieros. El decil de ingresos del hogar aparece con signo 


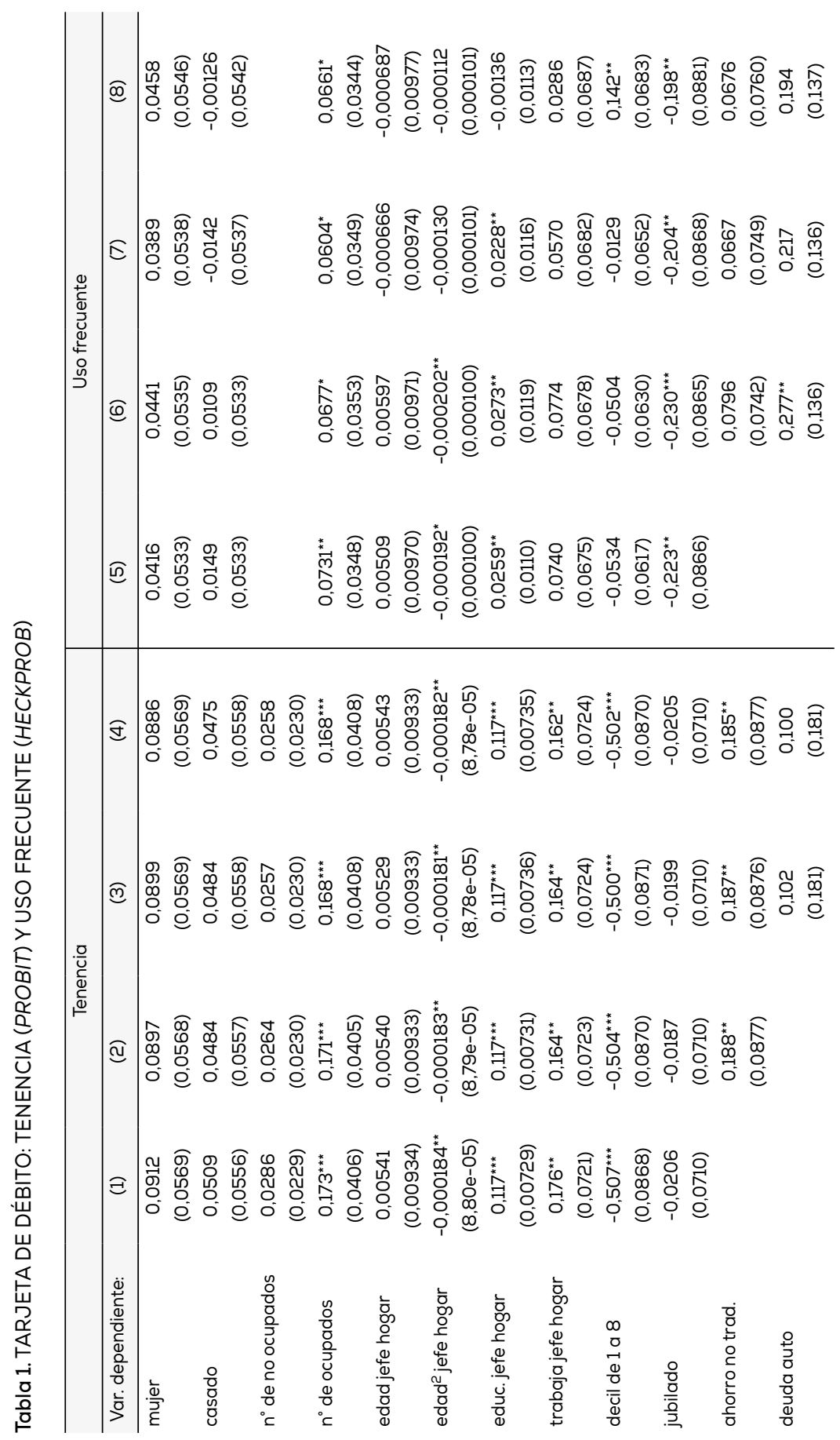




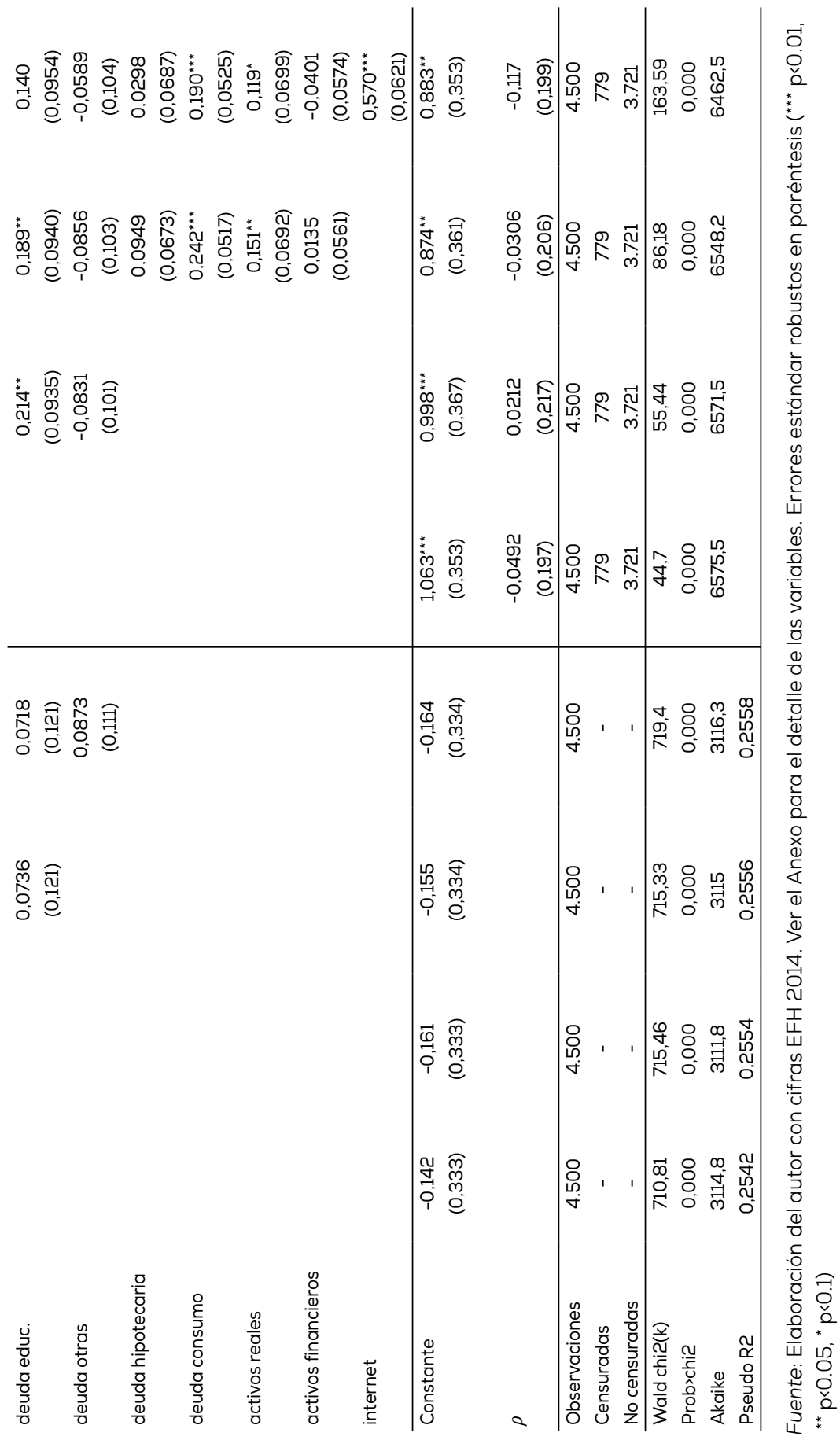


positivo, pero esto se explica por la alta correlación con la variable de educación, y podría estar tomando el efecto positivo de los años de escolaridad. Un resultado que llama la atención es que los jefes de hogar jóvenes no son más propensos que los de mayor edad a utilizar las tarjetas.

Analizando en conjunto ambas columnas vemos que, al igual que la tenencia, el uso frecuente no está determinado significativamente por el género del jefe de hogar, por lo que no hay evidencia de una brecha de género $y$, por lo tanto, no sería necesario definir políticas especialmente dirigidas a las mujeres. Allen et al. (2016) tampoco encuentran una diferencia por sexo en la tenencia de cuentas bancarias, pero sí una desventaja para las mujeres en su uso frecuente. La misma desventaja se encuentra en Perú (Cámara et al. 2014) y en México (Peña et al. 2014). Así, el caso chileno tendría un rasgo distintivo y positivo, ya que las mujeres han logrado acceder en igual medida que los hombres a los beneficios de usar una tarjeta de débito.

Por otro lado, encontramos que la práctica del ahorro no bancario (medida acá como la tenencia de ahorros a través de pollas, negocios familiares, etcétera) favorece la tenencia de tarjetas de débito, mientras que la tenencia de deudas de consumo y activos reales influye en su uso frecuente. En este contexto, de nuestros resultados se podría inferir una política tanto a favor del fomento del ahorro y del crédito, el primero con efectos sobre tenencia y el segundo sobre uso efectivo, aunque lo que se presenta acá no debería interpretarse como efecto causal. Los demás trabajos para economías en desarrollo encuentran evidencia mixta. Allen et al. (2016) a nivel internacional y Peña et al. (2014) para el caso de México encuentran un efecto positivo de la promoción del ahorro sobre la tenencia y el uso frecuente de cuentas bancarias, mientras que Cámara et al. (2014) encuentran un efecto positivo sobre su definición de inclusión financiera sólo para las deudas.

La tabla 2 repite la misma metodología, pero está referida a la tenencia y uso frecuente de la tarjeta de crédito bancaria. Nuevamente vemos que los modelos son significativos para cualquier nivel de significancia (excepto el de la columna 5 que no es significativo al uno por ciento).

En la columna 4 vemos que cuando el jefe de hogar es casado (incluye convivencia) y tiene más años de educación aumenta significa- 
tivamente su probabilidad de tener una tarjeta de crédito bancaria. Esto deja de manifiesto la importancia de la educación y, al mismo tiempo, revela que los solteros son un sector de la población donde aún puede mejorar la inclusión financiera. Al mismo tiempo, la tenencia de deudas automotrices también tiene un efecto positivo y estadísticamente relevante, lo que evidenciaría complementariedad entre el financiamiento del auto a través de crédito con la decisión de tener este tipo de tarjetas. Los ingresos del hogar tienen un efecto significativo: la probabilidad de tener tarjeta de crédito bancaria disminuye con los deciles de ingreso.

Respecto a la decisión de usarla, la columna 8 nos indica que dicha probabilidad es mayor cuando el jefe de hogar trabaja y en el hogar se utiliza internet. En relación con las deudas de consumo, al igual que en el caso de las tarjetas de débito se confirma que existe una complementariedad con el uso que podría aprovecharse (por ejemplo a través de beneficios especiales de parte de los bancos privados o campañas directas de instituciones del sector público). Los factores que influyen significativamente en la decisión de no utilizar la tarjeta son un mayor número de ocupados en el hogar - lo que podría explicarse porque una mayor disponibilidad de ingresos en el grupo familiar sustituye el uso de este tipo de crédito-; el tener deudas automotrices — factor que jugaba a favor de tener estas tarjetas-; y la edad, respecto de la cual, a diferencia del caso de las tarjetas de débito, vemos que los jóvenes sí son más propensos a usar con frecuencia su tarjeta de crédito bancaria que los de mayor edad.

El sexo del jefe de hogar nuevamente no tiene influencia estadísticamente significativa en explicar ni la tenencia ni el uso de la tarjeta de crédito bancaria. Marshall y Kaufmann (2013) también estiman un modelo probit sobre la tenencia de tarjetas de crédito bancarias entre los jóvenes menores de 29 años, y tampoco encuentran una diferencia por sexo. Llama la atención, a su vez, que no exista complementariedad entre la tenencia de activos reales o financieros y la probabilidad de tener y usar la tarjeta. Intuitivamente sería esperable un efecto positivo, tanto por factores de oferta (bancos más propensos a entregar este producto a personas con ahorros y activos) como de demanda (la tenencia de activos podría ser signo de cultura financiera). Por último, ni la educación del jefe de hogar ni el decil de ingresos son significativos, pero se debería a la multicolinealidad —o relación estrechísima — entre ambas variables. 


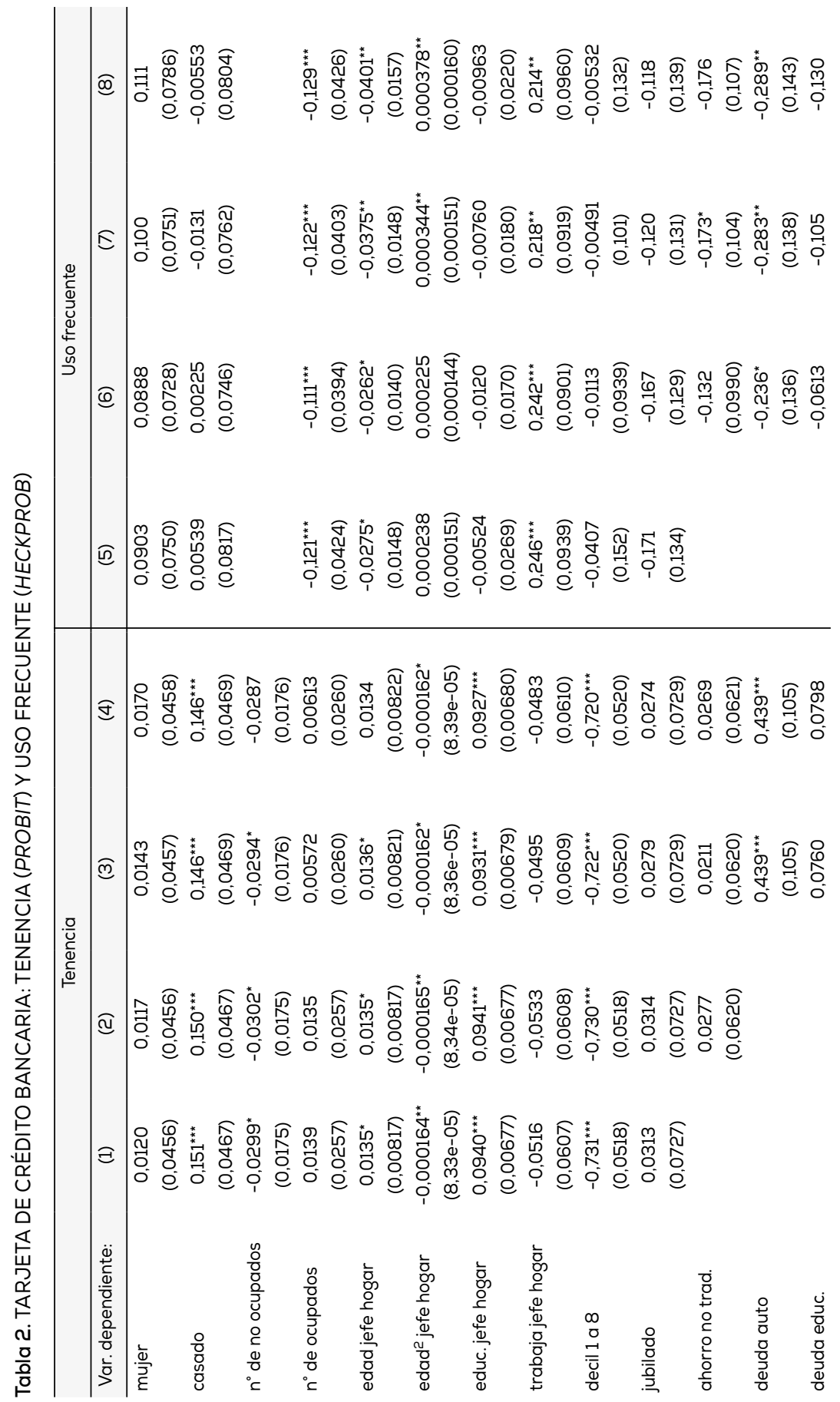




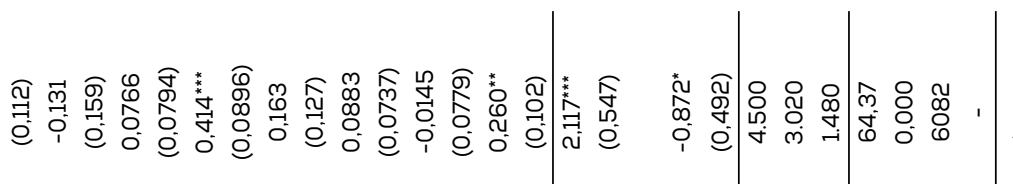

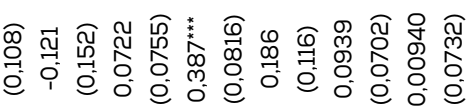

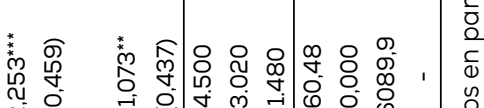
崔

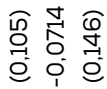

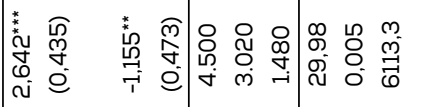

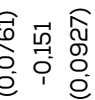

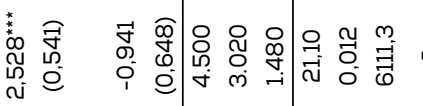

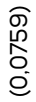

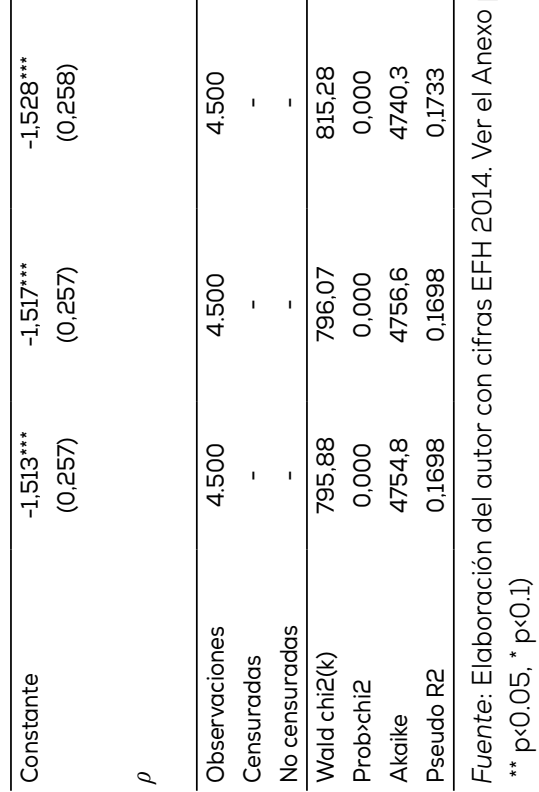




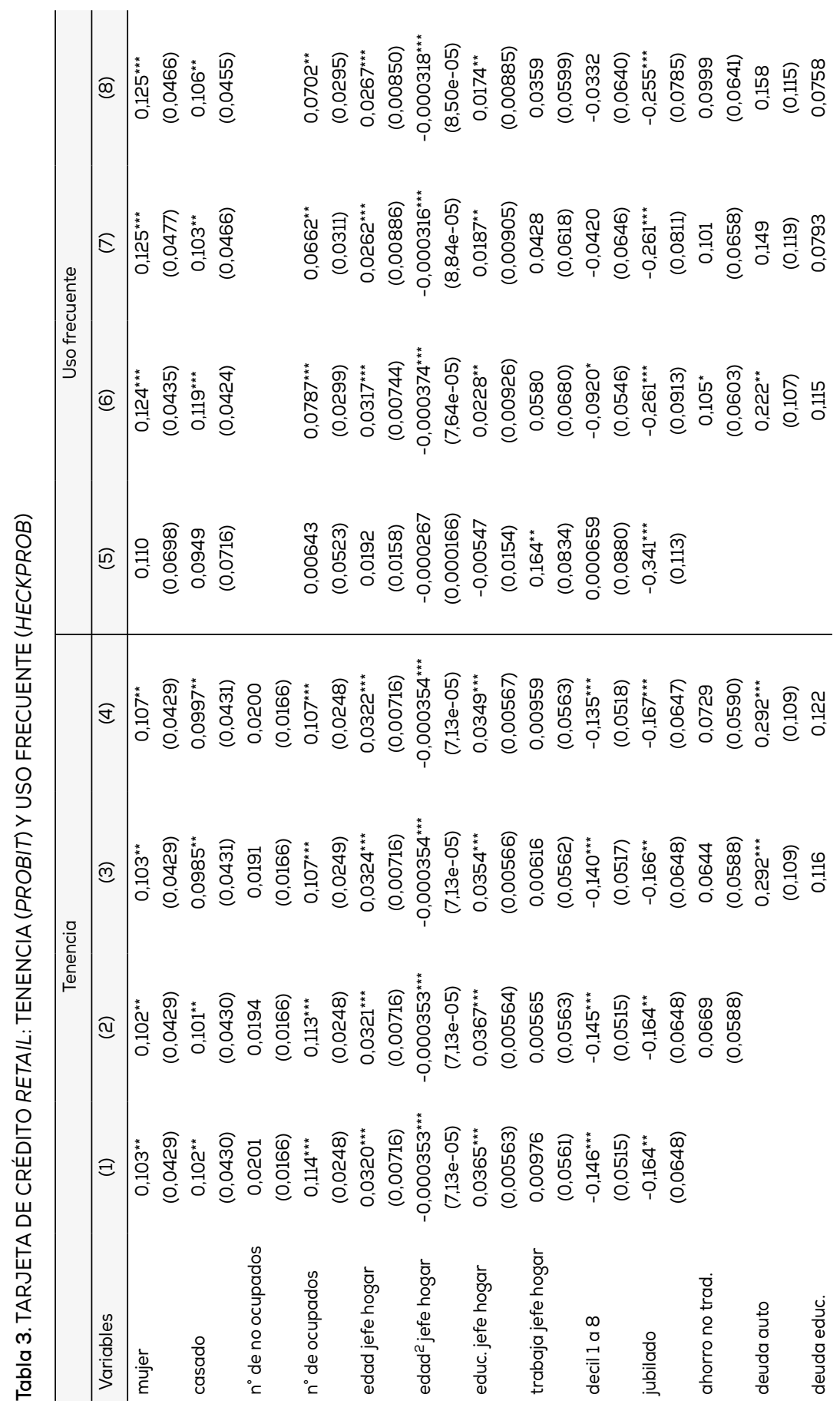




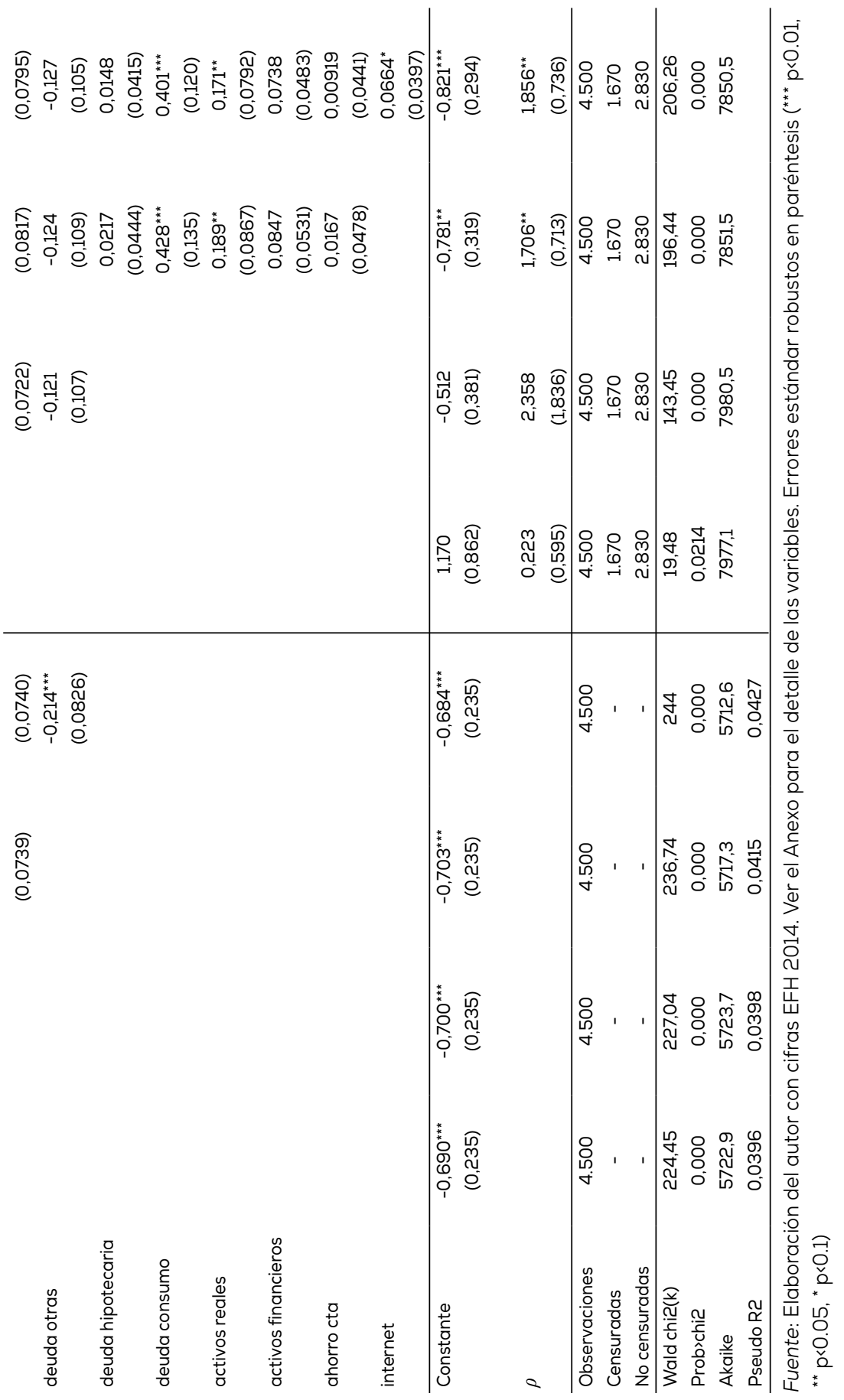


La variable que mide el uso de internet en el hogar resulta significativa para el uso de la tarjeta de crédito, tal como lo hacía en la tabla 1 para la de débito. Este factor no ha sido incluido en los demás trabajos comparables, por lo que no podemos contrastarlo, pero, intuitivamente, es coherente que el uso de internet favorezca la realización de compras y pagos utilizando estas tarjetas. De hecho, las nuevas tecnologías son uno de los pilares del esfuerzo del Banco Mundial por mejorar la inclusión financiera (Banco Mundial 2014).

A continuación, este trabajo mide cómo las tarjetas de crédito de casas comerciales han aportado a la inclusión financiera. Este es un producto financiero que no depende de los bancos y que, por años, ha competido con ellos en la provisión de créditos a través de tarjetas. En concreto, este estudio identifica qué tipo de hogares se han visto "incluidos" gracias a que son más propensos a tener y utilizar estas tarjetas en contraposición a las bancarias. La tabla 3 reporta el mismo modelo anterior para identificar los determinantes de su tenencia y su uso.

En la columna 4 vemos que aumenta significativamente la probabilidad de tener una tarjeta de casa comercial cuando el jefe de hogar es mujer, es casado o casada, tiene más edad y más años de educación. También aumenta la posibilidad cuando mayor es el número de ocupados en el hogar y cuando éste posee deudas automotrices. Los factores que influyen significativa y negativamente son la jubilación del jefe de hogar, los bajos ingresos y la tenencia de otras deudas (tales como préstamos de amigos y familiares).

Aquí es interesante resaltar las diferencias respecto a las tarjetas de crédito bancarias. En primer lugar, las jefas de hogar y aquellos de más edad tienen mayor probabilidad de tener una tarjeta de retail por sobre una bancaria. En segundo lugar, lo opuesto ocurriría entre los jefes de hogar jubilados. Tercero, la magnitud del efecto negativo del decil de ingresos es menor que en el caso de las tarjetas bancarias, lo que indicaría una mayor penetración del retail entre los hogares de más bajos ingresos (que confirma lo concluido a partir de la figura 2).

En la columna 8 vemos que los factores que favorecen significativamente el uso de estas tarjetas son ser jefe de hogar mujer, ser casado, tener mayor edad y tener más años de educación. En la misma dirección influyen la tenencia de deudas de consumo, activos reales y el uso de internet. En comparación al uso frecuente de las tarjetas de crédito 
bancarias, las jefas de hogar sí son más propensas a usar las tarjetas del retail y su situación laboral no es significativa en explicar su utilización. Además, la variable edad en este caso sí tiene un efecto positivo y estadísticamente relevante, lo que indicaría que, entre aquellos de más edad, existe una tendencia al empleo frecuente de estas tarjetas, en contraposición a lo que ocurre con las tarjetas bancarias.

\section{CONCLUSIONES Y RECOMENDACIONES DE POLÍTICA}

En este trabajo hemos mostrado que la inclusión financiera enfrenta un desafío relevante a la hora de conseguir que la población use efectivamente los productos que posee. Más allá de aquellos que no tienen o no utilizan los servicios financieros porque no los desean, la política pública debería poner especial atención en los individuos que, necesitando y pudiendo obtener estos servicios, no logran acceder a ellos por enfrentar un costo prohibitivo u otras trabas por el lado de la oferta. En este trabajo hemos identificado aquellos hogares que serían los más propensos a enfrentar este tipo de barreras, y en los que debería centrarse el diseño de políticas orientadas a aumentar la inclusión financiera en Chile.

Al centrar nuestro análisis en el uso, hemos investigado una dimensión de la inclusión que no ha sido estudiada hasta el momento en Chile. Aun cuando no necesariamente estamos en presencia de efectos causales, los resultados sugieren que una variable relevante es la educación y el ingreso, respecto de lo cual los hogares de deciles más bajos o con menores años de educación muestran menor tenencia y uso de las tarjetas. Esto es coherente con lo reportado en la Global Findex 2014, en la que el 44 por ciento de los que no poseen una cuenta de ahorro en una institución financiera declara como barrera el no contar con suficiente dinero, mientras el 42 por ciento manifiesta encontrarlas muy caras. Por ello, políticas que reduzcan los costos monetarios, de tiempo y de operación de las cuentas debieran tener un efecto positivo. Aunque es importante notar que, respecto al crédito a través de tarjetas, tanto las mujeres como los deciles más bajos se compensan por una mayor tenencia y uso de las tarjetas de crédito retail. Esto último aporta evidencia de que este sector puede ser un actor relevante en la inclusión financiera, y no debe descuidarse el desarrollo de esta industria y su adecuada regulación. 
Encontramos que la posesión de otros ahorros no financieros (en la forma de pollas, negocios familiares, etcétera) favorecen significativamente la bancarización, a través de una mayor tenencia de tarjetas de débito. Esto representa evidencia a favor de programas, tanto públicos como privados, que enseñen y promuevan el ahorro, especialmente entre la población excluida del sistema financiero. Asimismo, la posesión de deudas no financieras (automotrices, educacionales y otras) favorece la tenencia de tarjetas de crédito y el uso efectivo de éstas y de las de débito. Similar al caso del ahorro, esto sugiere los beneficios que se obtendrían de programas que eduquen y enseñen la experiencia del endeudamiento sostenible. Por el lado del uso, además, la tenencia de otros tipos de deudas financieras o activos reales favorece el uso efectivo tanto de las tarjetas de débito como de crédito, complementariedad que podría ser aprovechada por los actores del sector privado. Identificar y distinguir los mecanismos a través de los cuales opera esta complementariedad se abre como objetivo de la investigación futura.

La evidencia también favorece la idea de que un mayor uso efectivo podría lograrse a través de la masificación de servicios bancarios disponibles por internet. En este sentido, el mayor esfuerzo de innovación tecnológica de los bancos debiera continuar puesto en el desarrollo de la banca digital. En la misma línea, en nuestro país 5,4 millones de personas no tienen conexión a internet, 1,3 millones no acceden a una cobertura de banda ancha móvil $(3 \mathrm{G}+4 \mathrm{G})$ y 7,7 millones de personas tienen cobertura de banda ancha móvil pero no la usan. Al mismo tiempo, la principal barrera en nuestro país sería, entre otras, la falta de alfabetización y aptitudes digitales (Groupe Speciale Mobile Assotiation 2016). En este sentido, junto con los esfuerzos públicos y privados por la mejora en la cobertura de internet, tanto móvil como fija, debe promoverse el uso de esta red a través de los trámites cotidianos. Esto tendría un efecto secundario muy importante sobre la bancarización.

Dada la significancia de la educación en nuestros resultados, un elemento que no puede faltar en la discusión de la inclusión financiera en general es el fomento de la educación específicamente financiera entre la población. La evidencia reciente muestra que el nivel de ésta es extremadamente bajo a nivel mundial y es otro de los desafíos relevantes en la actualidad (Lusardi y Mitchell 2014), puesto que favorece un uso responsable de las tarjetas analizadas en este trabajo y previene el cometimiento de abusos por parte de los actores del sistema financiero. 


\begin{abstract}
ANEXO
Tabla A.1: DEFINICIÓN DE VARIABLES DE LA EFH 2014
\end{abstract}

\begin{tabular}{|c|c|}
\hline mujer & Valor 1 si el jefe de hogar es mujer, 0 en caso contrario \\
\hline casado & $\begin{array}{l}\text { Valor } 1 \text { si el jefe de hogar es casado o conviviente, } 0 \text { si es anulado, } \\
\text { separado, viudo, soltero o divorciado }\end{array}$ \\
\hline$n^{\circ}$ no ocupados & $\begin{array}{l}\mathrm{N}^{\circ} \text { de no ocupados en el hogar (desempleado, inactivo o fuera de } \\
\text { la población económicamente activa) }\end{array}$ \\
\hline$n^{\circ}$ ocupados & $N^{\circ}$ de ocupados en el hogar \\
\hline edad jefe hogar & Edad del jefe de hogar \\
\hline edad ${ }^{2}$ jefe hogar & Cuadrado de la edad del jefe de hogar \\
\hline educ. jefe hogar & Años de educación del jefe de hogar \\
\hline trabaja jefe hogar & Valor 1 si el jefe de hogar trabaja, 0 en caso contrario \\
\hline decil de 1 a 8 & $\begin{array}{l}\text { Valor } 1 \text { si el hogar se ubica entre los deciles } 1 \text { al } 8,0 \text { en caso con- } \\
\text { trario }\end{array}$ \\
\hline jubilado & $\begin{array}{l}\text { Valor } 1 \text { si el jefe de hogar está pensionado, retirado o similar, } 0 \text { en } \\
\text { caso contrario }\end{array}$ \\
\hline ahorro no trad. & $\begin{array}{l}\text { Indica si el hogar ahorra o guarda dinero en otras formas alter- } \\
\text { nativas (a través de una polla, mediante compra/venta de acti- } \\
\text { vos, inversiones en negocios de familiares, etc.) }\end{array}$ \\
\hline deuda auto & Indica si algún miembro del hogar posee crédito automotriz \\
\hline deuda educ. & Indica si algún miembro del hogar posee deudas educacionales \\
\hline deuda otras & $\begin{array}{l}\text { Indica si los hogares poseen deuda asociada a: préstamos de } \\
\text { parientes o amigos, créditos de prestamistas, casa de crédito } \\
\text { prendario, pedir fiado, créditos de otras fuentes (empleador, sin- } \\
\text { dicato, etc.) }\end{array}$ \\
\hline deuda hipotecaria & $\begin{array}{l}\text { Indica si el hogar posee deuda hipotecaria, ya sea asociada al } \\
\text { financiamiento de la vivienda principal o a otras propiedades } \\
\text { inmobiliarias. }\end{array}$ \\
\hline deuda consumo & $\begin{array}{l}\text { Indica si los hogares poseen deuda asociada a: tarjetas de cré- } \\
\text { dito bancarias, lineas de crédito, créditos de consumo bancarios } \\
\text { o en financieras, tarjetas de crédito de casas comerciales u otras } \\
\text { instituciones no bancarias, préstamos de consumo en casas co- } \\
\text { merciales (avances en efectivo) o créditos en cajas de compensa- } \\
\text { ción, cooperativas u otras similares. }\end{array}$ \\
\hline activos reales & $\begin{array}{l}\text { Indica si el hogar posee activos inmobiliarios (vivienda principal u } \\
\text { otras propiedades), activos en forma de vehículos u otros activos } \\
\text { reales. }\end{array}$ \\
\hline activos financieros & $\begin{array}{l}\text { Indica si el hogar posee ahorros en algún tipo de instrumento fi- } \\
\text { nanciero, ya sea de renta fija o variable. }\end{array}$ \\
\hline ahorro cta & $\begin{array}{l}\text { Indica si el hogar mantiene dinero en su cuenta corriente o vista, } \\
\text { en forma de ahorro. }\end{array}$ \\
\hline internet & $\begin{array}{l}\text { Indica si algún miembro del hogar utiliza los servicios de banca } \\
\text { por internet }\end{array}$ \\
\hline
\end{tabular}




\section{REFERENCIAS CITADAS}

Allen, Franklin, Asli Demirguc-Kunt, Leora Klapper \& Maria Martinez Peria. 2016. "The Foundations of Financial Inclusion. Understanding Ownership and Use of Formal Accounts". Journal of Financial Intermediation 27: 1-30.

Arcand, Jean-Louis, Enrico Berkes \& Ugo Panizza. 2012. "Too Much Finance?". IMF Working Paper 12/161. International Monetary Fund. www.imf.org/ external/publications/pubindadv.htm.

Banco Mundial. Global Financial Development Report 2014 - Financial Inclusion. 2014. http://www.worldbank.org/en/publication/gfdr.

Beck, Thorsten \& Augusto de la Torre. 2006. "The Basic Analytics of Access to Financial Services". Policy Research Working Paper 4026. Banco Mundial. http://dx.doi.org/10.1596/1813-9450-4026.

Beck, Thorsten, Asli Demirguc-Kunt \& Ross Levine. 2007a. "Finance, Inequality and the Poor". Journal of Economic Growth 12 (1): 27-49.

—. 2007b. "Reaching Out: Access to and Use of Banking Services Across Countries". Journal of Financial Economics 85: 234-266.

— 2008. "Banking Services for Everyone? Barriers to Bank Access and Use around the World". The World Bank Economic Review 22 (3): 397-430.

Cámara, Noelia \& David Tuesta. 2014. "Factors that Matter for Financial Inclusion: Evidence for Peru". The International Journal of Finance 10: 10-31.

Campbell, Dennis, F. Asís Martínez-Jerez \& Peter Tufano. 2012. "Bouncing Out of the Banking System: An Empirical Analysis of Involuntary Bank Account Closures". Journal of Banking \& Finance 36: 1224-1235.

- Cecchetti, Stephen \& Enisse Kharroubi. 2012. "Reassessing the Impact of Finance on Growth". BIS Working Papers 381. Bank of International Settlements. http://www.bis.org/publ/work381.htm.. 2015. "Why Does Financial Sector Growth Crowd Out Real Economic Growth?”. BIS Working Papers 490. Bank of International Settlements. http://www.bis.org/publ/ work490.htm.

Cull, Robert, Tilman Ehrbeck \& Nina Holle. 2014. "Financial Inclusion and Development: Recent Impact Evidence". Focus Note 92 (CGAP).

Demirguc-Kunt, Asli, Leora Klapper, Dorothe Singer \& Peter van Oudheusden. 2015. "The Global Findex Database 2014. Measuring Financial Inclusion around the World". Policy Research Working Paper 7.255. Banco Mundial. http://documents.worldbank.org/curated/en/2015/04/24368699/global-findexdatabase-2014-measuring-financial-inclusion-around-world.

Djankov, Simeon, Pedro Miranda, Enrique Seira \& Siddharth Sharma. 2008. "Who Are the Unbanked?". Policy Research Working Paper 4.647. Banco Mundial.

Greene, William \& Sherrie Rhine. 2013. "Factors that Contribute to Becoming Unbanked”. Journal of Consumer Affairs 47 (1): 27-36.

Greenwood, Jeremy \& Boyan Jovanovic. 1990. "Financial Development, Growth and the Distribution of Income". Journal of Political Economy 98 (5): 1076-1107. 
Groupe Speciale Mobile Assotiation. 2016. "Inclusión Digital en América Latina y el Caribe". https://gsmaintelligence.com/research/?file=bc2039b5cc 86be21d1299ba3a7b1bde2\&download.

Karlan, Dean \& Jonathan Morduch. 2009. “Access to Finance”. En Handbook of Development Economics, vol. 5, editado por Dani Rodrik \& Mark Rosenzweig.

Lusardi, Annamaria \& Olivia Mitchell. 2014. "The Economic Importance of Financial Literacy: Theory and Evidence". Journal of Economic Literature 52 (1): 5-44.

Marshall, Enrique. 2015. "Reflexiones sobre la práctica del ahorro en Chile". Documentos de Política Económica 54. Banco Central de Chile. http://www. bcenral.cl.

Marshall, Enrique \& Cristóbal Kaufmann. 2013. "Acceso de los jóvenes a los servicios financieros: realidades y desafíos". Documento de Política Económica 46. Banco Central de Chile. http://www.bcentral.cl.

Peña, Ximena, Carmen Hoyo \& David Tuesta. 2014. "Determinantes de la inclusión financiera en México a partir de la ENIF 2012". Documento de Trabajo 14/14. BBVA Research. https://www.bbvaresearch.com/category/tipos-dedocumento/documento-de-trabajo/.

Sahay, Ratna, Martin Cihak, Papa N'Diaye, Adolfo Barajas, Ran Bi, Diana Ayala, Yuan Gao, Annette Kyobe, Lam Nguyen, Christian Saborowski, Katsiaryna Svirydzenka \& Seyed Reza Yousefi. 2015. "Rethinking Financial Deepening: Stability and Growth in Emerging Markets". IMF Staff Discussion Note 15/08. Fondo Monetario Internacional. https://www.imf.org/external/pubs/cat/ longres.aspx? sk=42868.0.

Tuesta, David, Gloria Sorensen, Adriana Haring \& Noelia Cámara. 2015. "Inclusión financiera y sus determinantes: el caso argentino". Documento de Trabajo 15/04. BBVA Research. https://www.bbvaresearch.com/category/ tipos-de-documento/documento-de-trabajo/.

Van de Ven, Wynand \& Bernard van Praag. 1981. "The Demand for Deductibles in Private Health Insurance: A Probit Model with Sample Selection". Journal of Econometrics 17 (2): 229-52. EP 